\title{
Periodontal status of Białystok citizens aged 65-74 years: A pilot study
}

\section{Stan przyzębia mieszkańców Białegostoku w wieku od 65 do 74 lat - badania wstępne}

\author{
Magdalena Sulewska ${ }^{1, B-D}$, Jan Pietruski², C, E, F, Edyta Sulima ${ }^{3, B, D}$, Rafał Świsłocki², B, D, Agnieszka Paniczko ${ }^{4, B}$, Ewa Duraj”,, \\ Małgorzata Pietruska ${ }^{1, A, C, E, F}$ \\ 1 Department of Periodontology, Medical University of Bialystok, Białystok, Poland \\ 2 Private Practice, Białystok, Poland \\ 3 Individual Medical Pracice Edyta Sulima, Wasilków, Poland \\ ${ }^{4}$ Non-public Healthcare Institute "Agmed", Białystok, Poland \\ A - research concept and design; $\mathrm{B}$ - collection and/or assembly of data; $\mathrm{C}$ - data analysis and interpretation; \\ $D$ - writing the article; $E$ - critical revision of the article; $F$ - final approval of article
}

\section{Address for correspondence}

Magdalena Sulewska

E-mail: cholewa.magda@gmail.com

Funding sources

none declared

Conflict of interest

none declared

Received on January 19, 2017

Revised on January 23, 2017

Accepted on April 26, 2017

DOI

$10.17219 / \mathrm{dmp} / 70772$

Copyright

() 2017 by Wroclaw Medical University

and Polish Dental Society

This is an article distributed under the terms of the

Creative Commons Attribution Non-Commercial License

(http://creativecommons.org/licenses/by-nc-nd/4.0/)

\section{Abstract}

Background. Routine epidemiology examinations of the periodontium in adults (regional and supraregional) are necessary to evaluate their health and to undertake proper preventative actions (prophylactic and therapeutic) pertaining to periodontitis.

Objectives. The aim of the study was to evaluate the oral hygiene and periodontal status of citizens aged 65-74 years residing in a big city in the Podlaskie province.

Material and methods. The study included 72 randomly chosen Białystok citizens (51 women and 21 men). While recording the patients' medical history, special attention was paid to cigarette smoking. The condition of oral hygiene and periodontal status were evaluated. The following parameters were tested: API (approximal plaque index), PI (plaque index), BOP (bleeding on probing), PD (probing depth) and CAL (clinical attachment level). Moreover, the mean number of preserved teeth, the percentage of persons with at least 20 preserved natural teeth and the percentage of edentulism were evaluated.

Results. Mean API was 66.16\% \pm 47.33, PI $-57.82 \% \pm 49.39$ while BOP $-26.74 \% \pm 44.27$. PD was estimated at $2.13 \mathrm{~mm} \pm 1.62$, while the loss of CAL was found in $61.08 \pm 27.43$ sites. The coefficient of nicotine addiction was $675 \pm 475.13$. The mean number of preserved teeth was $13.36 \pm 8.18$, while maintained chewing function was found in $27.78 \%$ of the individuals and edentulism in $12.5 \%$ of the cases.

Conclusions. The periodontal status of Białystok citizens aged 65-74 years is unsatisfactory. The percentage of persons with preserved chewing function is low and thus the need for periodontal treatment and rehabilitation of the masticatory apparatus is high.

Key words: epidemiology, periodontal status, gerontology

Słowa kluczowe: epidemiologia, stan przyzębia, gerostomatologia 
Periodontitis may affect as much as $90 \%$ of the world population and thus is considered a civilizational disease. ${ }^{1}$ Both the evaluation of periodontal disease incidence and the presence of correlations between periodontal disorders and general health condition are one of the main objectives of epidemiological studies. Periodic examinations on the individuals aged 65-74 years included in the retired group are conducted in all developed countries. The observations of both periodontitis and the number of teeth in this age group reflect the outcomes of the prophylactic actions and dental treatment performed so far, but they may also explain the clinical course of a number of civilization diseases, e.g. diabetes, atherosclerosis or osteoporosis. $^{2}$

Demographic data indicates that $15 \%$ of the world's population in 2025 will be over 60 years of age. ${ }^{3}$ According to $\mathrm{WHO}$, there will be 2 billion people over 60 years of age in $2050,80 \%$ of which will comprise the population of developing countries. ${ }^{4}$ In Poland in $1989,10 \%$ of society was over 60 years of age. ${ }^{5}$ According to statistical data by GUS (Central Statistical Office of Poland), in 2020, 22.4\% of Polish society will be over 60 years of age and $1 / 3$ of this amount will be over 75 years of age. ${ }^{6}$ The ageing of society will be accompanied by the increase in health needs, including those pertaining to the oral cavity. Therefore, monitoring the status of oral health is extremely important for establishing pro-health activities aimed at improving the health of the oral cavity.

Due to the increasing ratio of seniors, every gerostomatologic examination, which includes the number of preserved teeth, the percentage of persons with at least 20 natural teeth and the percentage of edentulism, is of great value. ${ }^{7}$ The comparison of current monitoring outcomes with earlier results allows us to evaluate the changes in dental status. ${ }^{8}$

The 65-74 years age group in Poland was first included in epidemiology studies in 1998. Further national research was carried out in 2002 and 2009. ${ }^{89}$ The presented research constituted a part of a national project conducted in the years 2013-2014 and was aimed at the evaluation of the oral cavity health status as well as periodontal status in a large urban agglomeration in the Podlaskie province.

\section{Material and methods}

The study was conducted in the area of Białystok city and included randomly chosen citizens aged 65-74 years. The invitation for the examination was sent to 1,000 people, yet only 72 persons including 51 women and 21 men reported for the examination (mean age $68.57 \pm 3.22$ ).

The exclusion criteria for periodontal examination were general contraindications (e.g. history of bacterial endocarditis) and local ones (e.g. acute odontogenic conditions).

Medical history included the data pertaining to cigarette smoking. Smoking coefficient calculated as the product of the number of cigarettes smoked per day and the duration of the addiction was used for the evaluation.

A clinical study was performed with the use of periodontal probe (PCPUNC 15, Hu-Friedy, USA) with a scale in millimeters. The examining personnel (dentists) had undergone standard calibration training. The study was conducted using a program financed by the Ministry of Health Evaluation to investigate the health condition of the oral cavity in the Polish population aged 35-44 and 65-74 years and was approved by the Bioethics Commission of the Medical University of Bialystok (R-I-002/266/2009).

The physical examination included the evaluation of oral hygiene and periodontal status with the use of the following parameters: plaque index (PI) by O'Leary, ${ }^{10}$ approximal plaque index (API) by Lange et al., ${ }^{11}$ bleeding on probing (BOP) by Ainamo \& Bay, ${ }^{12}$ probing depth (PD) and clinical attachment level (CAL). PI, BOP, PD and CAL were assessed at 4 aspects: buccal, palatal/lingual, mesial and distal. PD was defined as the distance between gingival margin and sulcus/pocket bottom detected with the probe. CAL was defined as the distance between sulcus/ pocket bottom identified with the probe and cementoenamel junction.

Moreover, the number of pockets with $\mathrm{PD}>5 \mathrm{~mm}$ and the sites with the loss of attachment CAL $\geq 3 \mathrm{~mm}$ and CAL $>5 \mathrm{~mm}$ were determined. The percentage [\%] of individuals with CAL $\geq 3 \mathrm{~mm}$ and CAL $>5 \mathrm{~mm}$ as well as individuals with PI, API $<25 \%$ and BOP less than $20 \%$ were established. Also, the mean number of preserved teeth, the percentage of persons with at least 20 preserved natural teeth and the percentage of edentulism were evaluated.

Third molars were not taken into consideration in the research. In the case of teeth with permanent prosthetic restorations, the reference point was apical margin of the prosthetic restoration. The obtained values were presented in numbers rounded to the nearest millimeter.

The statistical analysis was performed with the use of STATISTICA 12.0 StatSoft (StatSoft. Tulsa, USA) software. Non parametric U Mann-Whitney test was used for the comparison between the groups. Spearman's rank order correlation coefficient was also determined. The results were considered statistically significant at $\mathrm{p}$-value $<0.05$.

\section{Results}

The results indicate that Białystok citizens aged 65-74 years exhibit a poor oral cavity health. It was observed that oral hygiene is unsatisfactory, which may be confirmed by the high mean values of the evaluated hygiene coefficients.

According to observations, mean API value was $66.16 \% \pm 47.33$, which is indicative of quite poor oral hygiene. The percentage of persons with proper oral hygiene (API $<25 \%$ ) was $12.7 \%$ and was independent of gender. 
Mean PI value was $57.82 \% \pm 49.39$ and was slightly higher in the group of women $(0.59 \pm 0.49)$ as compared to the group of men $(0.57 \pm 0.49)$. The percentage of in-

Table 1. Qualitative and quantitative data in the study group of Białystok citizens aged $65-74$ years (mean \pm standard deviation)

\begin{tabular}{|l|c|c|}
\multicolumn{1}{|c|}{ Parametr } & Mean & $\begin{array}{c} \pm \text { Standard } \\
\text { deviation }\end{array}$ \\
\hline Age & 68.57 & \pm 3.22 \\
Number of teeth & 13.36 & \pm 8.18 \\
API & 0.66 & \pm 47.33 \\
PI & 57.82 & \pm 49.39 \\
BOP & 26.74 & \pm 44.27 \\
PD & 2.13 & \pm 1.62 \\
Number of pockets with $\mathrm{PD}>5 \mathrm{~mm}$ & 0.79 & \pm 1.74 \\
The sites with loss of CAL & 61.08 & \pm 27.43 \\
The sites with loss of CAL $\geq 3$ & 27.51 & \pm 15.62 \\
The sites with loss of CAL $>5 \mathrm{~mm}$ & 3.08 & \pm 4.71 \\
The percentage of persons with $\mathrm{API}<25 \%$ & $12.70 \%$ & \\
The percentage of persons with $\mathrm{PI}<25 \%$ & $14.29 \%$ & \\
The percentage of persons with $\mathrm{BOP}<20 \%$ & $46.03 \%$ & \\
The percentage of persons with $\mathrm{PD}>5 \mathrm{~mm}$ & $28.57 \%$ & \\
The percentage of persons with $\mathrm{CAL} \geq 3 \mathrm{~mm}$ & $100 \%$ & \\
The percentage of persons with $\mathrm{CAL}>5 \mathrm{~mm}$ & $57.14 \%$ & \\
The percentage of persons with loss of CAL & $100 \%$ & \\
The coefficient of nicotine $(\mathrm{n}=6$ ) & 675 & \pm 47.13 \\
\hline
\end{tabular}

* The group excluding the individuals with edentulism: 72-9=63; $n$ - number of people. dividuals who effectively brushed their teeth was $14.29 \%$ (Table 1 and 2).

According to estimations, the mean BOP value was $26.74 \% \pm 44.27$. No correlation between this parameter and gender was observed. The percentage of persons with mild symptoms of inflammation, which is BOP $<20 \%$, was $46.03 \%$ and was not related to gender.

In the elderly group, the mean PD value was $2.13 \mathrm{~mm}$ \pm 1.62 and was not related to gender. According to observations, men had deeper pockets $(2.19 \pm 1.08)$ than women $(2.10 \pm 1.21)$. The number of deep pockets of PD $>5 \mathrm{~mm}$ was $0.79 \pm 1.74$.

Mean number of sites with the loss of attachment was $61.08 \pm 27.43,45.39 \pm 32.45$ in women and $70.61 \pm 26.58$ in men ( $\mathrm{p}=0.0009)$. In $100 \%$ of the group CAL was found to be $\geq 3$ and $>5 \mathrm{~mm}$ in $57.14 \%$.

According to observations, smoking coefficient was 675 \pm 475.13 and was higher in women $(912.5 \pm 352.07)$ than in men $(200 \pm 282.84)$. In the case of seniors, active smokers constituted $8.33 \%$ of the examined individuals (6 persons) (Table 1 and 2).

Nine ( 8 women and 1 man) out of 72 individuals aged 65-74 years, which was $12.5 \%$, were edentate. The mean number of teeth present in the mouth was $13.36 \pm 8.18$ while the persons with maintained chewing function (with over $20 \mathrm{left}$ ) constituted $27.78 \%$ of the study group (20 individuals). In the case of women, the number of preserved teeth was significantly lower $(11.35 \pm 8.11)$ as compared to men $(17.65 \pm 6.64)$ (Table 2 and 3 ).

Table 2. Qualitative and quantitative data of Białystok citizens aged 65-74 years depending on gender (mean \pm standard deviation)

\begin{tabular}{|c|c|c|c|c|c|}
\hline Parameter & \multicolumn{2}{|c|}{ Female $(n=49)$} & \multicolumn{2}{|c|}{ Male $(n=23)$} & \\
\hline Age & 69 & \pm 3.20 & 67.62 & \pm 3.13 & 0.0976 \\
\hline Number of (preserved) teeth & 11.35 & \pm 8.11 & 17.65 & \pm 6.64 & 0.0009 \\
\hline API & 0.66 & \pm 0.47 & 0.67 & \pm 0.47 & 0.0174 \\
\hline $\mathrm{PI}$ & 0.59 & \pm 0.49 & 0.57 & \pm 0.49 & 0.6117 \\
\hline $\mathrm{BOP}$ & 0.28 & \pm 0.45 & 0.25 & \pm 0.43 & 0.3022 \\
\hline PD & 2.10 & \pm 1.21 & 2.16 & \pm 1.08 & 0.0983 \\
\hline Number of pockets with PD $>5 \mathrm{~mm}$ & 0.78 & \pm 1.80 & 0.82 & \pm 1.68 & 0.9343 \\
\hline CAL & 2.69 & \pm 1.56 & 2.72 & \pm 1.50 & 0.5708 \\
\hline The sites with loss of CAL & 45.39 & \pm 32.45 & 70.61 & \pm 26.58 & 0.0009 \\
\hline The sites with loss of CAL $\geq 3 \mathrm{~mm}$ & 20.73 & \pm 15.91 & 31.17 & \pm 18.12 & 0.023 \\
\hline The sites with loss of CAL > $5 \mathrm{~mm}$ & 2.22 & \pm 3.91 & 3.69 & \pm 5.56 & 0.2615 \\
\hline The percentage of persons with API $<25 \%$ & $12.19 \%$ & & $13.63 \%$ & & 0.8749 \\
\hline The percentage of persons with $\mathrm{Pl}<25 \%$ & $12.19 \%$ & & $18.18 \%$ & & 0.5482 \\
\hline The percentage of persons with BOP $<20 \%$ & $41.46 \%$ & & $54.54 \%$ & & 0.3334 \\
\hline The percentage of persons with PD $>5 \mathrm{~mm}$ & $29.27 \%$ & & $27.27 \%$ & & 0.8697 \\
\hline The percentage of persons with $C A L \geq 3 \mathrm{~mm}$ & $100 \%$ & & $100 \%$ & & \\
\hline The percentage of persons with CAL > $5 \mathrm{~mm}$ & $56.10 \%$ & & $59.09 \%$ & & 0.8229 \\
\hline The percentage of persons with loss of CAL & $100 \%$ & & $100 \%$ & & \\
\hline The coefficient of nicotine $(n=6)$ & 912.5 & \pm 352.07 & 200 & \pm 282.84 & 0.087 \\
\hline
\end{tabular}

*The group excluding the individuals with edentulism: $51-8=43$. ${ }^{*}$ The group excluding the individuals with edentulism: $21-1=20$. $n-$ number of people. 


\section{Discussion}

The aim of the study was to evaluate oral cavity hygiene and selected periodontal parameters in a group of Białystok citizens aged 65-74 years. Considering the increasing number of people over 60 years of age in the population, the study seems to be very up-to-date. The ageing of the population will be accompanied by increased health needs, including those pertaining to oral cavity health. ${ }^{3-6,13-15}$ The study presents issues related to the next couple of decades. Assuming that the estimation of API is the most objective evaluation of the effectiveness of the conducted hygienic procedures, it was observed that the study group showed an average oral hygiene while proper hygiene was found only in $12.7 \%$ of the individuals. However, the obtained own results are quite optimistic compared to the study carried out in 2012 on a group of male patients aged 65-74 years living in Białystok. ${ }^{3}$ In that study API value was higher by $7 \%$ and amounted to $74.0 \%$ while optimal hygiene was found only in $8.8 \%$ of persons. ${ }^{3}$

In a Kraków study on patients aged 71-80 years, the mean oral hygiene index (OHI) value of 2.2 was found to be unsatisfactory and required the improvement of hygienic habits. ${ }^{16}$ In own research, $14.29 \%$ of study group was found with good oral hygiene.

Epidemiology research on elderly groups in large cities in Poland were conducted in 1998, 2002 and 2009 with the use of CPITN (community periodontal index of treatment needs) which provides a general evaluation of both periodontal status and related therapeutic needs. ${ }^{8,9}$ One of the major limitations of this parameter is the lack of the possibility to establish the incidence of periodontitis. Therefore, more accurate parameters evaluating the status of periodontal tissues were used in own study. ${ }^{17,18}$ The analysis included the currently preferred probing depth measurement and clinical attachment level. ${ }^{19,20}$ Studies with the use of these parameters have been carried out in Poland only since 2013 on the age group of 65-74 years and thus there are certain limitations to comparing them to earlier observations. ${ }^{2,7}$

In own research, the mean BOP value was estimated to account for $26.74 \% \pm 44.27$, with a high percentage - 46.03\% of patients with mild inflammatory symptoms (BOP $<20 \%)$. The value of these parameters cannot be compared to the calculations performed in the previous studies of CPITN. CPI1 indicates the presence of bleeding on probing, yet this symptom may also be present in CPI2, CPI3 and CPI4. The interpretation of the precense of bleeding based exclusively on CPI1 may lower its value while adding up the values of CPI2, CPI3 and CPI4 may overly increase it.

In the case of the examined population of Białystok citizens aged 65-74 years, the mean value of probing depth was $2.13 \mathrm{~mm} \pm 1.62$, while the number of pockets over $5 \mathrm{~mm}$ deep was $0.79 \pm 1.74$. The monitoring of periodon-
Table 3. Dental status of Białystok citizens aged 65-74 years

\begin{tabular}{|l|c|c|c|c|}
\hline \multirow{2}{*}{\multicolumn{1}{c|}{ Parameter }} & \multicolumn{5}{c|}{ Study group $(n=72)$} \\
\cline { 2 - 6 } & $n$ & $\%$ & $\begin{array}{c}\text { female } \\
(n=51)\end{array}$ & $\begin{array}{c}\text { male } \\
(n=21)\end{array}$ \\
\hline Mentained $\geq 20$ natural teeth & 20 & 27.78 & 8 & 12 \\
Edentulism in the maxilla & 10 & 13.89 & 10 & 0 \\
Edentulism in the mandible & 2 & 2.78 & 2 & 0 \\
Edentulism (maxilla + mandible) & 9 & 12.5 & 8 & 1 \\
\hline
\end{tabular}

$n$ - number of people.

tal status in 1998, 2002 and 2009 revealed the presence of deep pockets of at least $6 \mathrm{~mm}$ in 9.9, 2.3 and $1.6 \%$ at the analyzed intervals, respectively. ${ }^{8}$ In the study conducted in 2012 by Szpak et al.evaluating the periodontal status and therapeutic needs among 106 male patients aged 65-74 years living in Białystok, a healthy periodontium was found (CPI0) in 6 persons, which constituted $5.7 \%$ of the group. ${ }^{3}$ In the highest percentage of patients (20.8\%), shallow pockets were observed (CPI3), while male patients with over $6 \mathrm{~mm}$ deep pockets constituted $19.8 \%$ of the examined individuals.

According to own research, the percentage of persons with PD > $5 \mathrm{~mm}$ was estimated to be $28.57 \%$. Loss of attachment was present in $100 \%$ of individuals, with CAL $>3 \mathrm{~mm}$ and CAL $\geq 5 \mathrm{~mm}$ value $100 \%$ and $57.14 \%$, respectively. The obtained results correlate with American observations NHANES, where the percentage of CAL $>5 \mathrm{~mm}$ was observed in $67.1 \%$ of individuals over 65 years of age. ${ }^{21}$ A stronger correlation was found between CAL and age compared with PD and age, which was previously noticed by Thornton-Evans et al. in 2013. ${ }^{22}$ These observations are confirmed by a number of epidemiology studies which indicate a higher incidence of periodontitis in older persons. ${ }^{22-24}$ These correlations are based on both biological processes, which accompany body aging as well as the accumulating effects of dental plaque and environmental factors, which include risk factors.

In the case of Białystok seniors, active smokers constituted $8.33 \%$ of the patients while 29 individuals were smokers in the past. Past and present smokers were found to be a large group of 35 people (48.6\% of the examined population). Smoking is very common in Poland and affects $33 \%$ of men and $20 \%$ of women. ${ }^{25}$ The highest percentage of smokers can be found in the age group of 40-59 years with vocational education. In terms of smoking, Poland has the $9^{\text {th }}$ (men) and $8^{\text {th }}$ (women) place in European rating. ${ }^{21,25}$ Smoking tobacco is a generally acknowledged risk factor in developing periodontitis and its influence is manifested by a worse response to periodontal treatment. ${ }^{26}$ In NHANES study in 2009-2010, the incidence of periodontitis among smokers amounted to $64.2 \%$ compared to $39.8 \%$ in non-smokers. ${ }^{22}$ Pockets of PD over $5 \mathrm{~mm}$ were present in $34.1 \%$ of smokers and $14.5 \%$ of non-smokers. ${ }^{27}$ Despite greater tissue damage, inflammation symptoms (bleeding) are less visible in 
smokers, which are related to the constriction of vessels caused by nicotine. The described phenomenon may be responsible for the high percentage of persons (46.03\%) with mild inflammatory symptoms in the study group.

A comparative analysis of a supraregional study of the periodontal status in Poland indicates that the periodontal status has deteriorated in the recent studies: only $1.2 \%$ of people with CPIO and considerably higher percentage - over $41 \%$ of people with pockets over $3.5 \mathrm{~mm}^{2}$. A healthy periodontium expressed by CPIO value in the analyzed age group in 1998, 2002 and 2009 was detected in 3.7, 4.8 and $7.8 \%$ of patients, respectively while the percentage in periodontitis patients (CPI3 and 4) in 39.1, 14.0 and 9.2\%, respectively. ${ }^{8}$ These results were influenced by an increasingly higher number of preserved teeth at this age.

Compared to the studies carried out in 2002 and 2009, a considerable - over 2-fold increase in the number of preserved teeth in Polish people in the analyzed age group can be observed. Poland reached European level in these terms. In this study, the mean number of preserved teeth in Białystok citizens was 13.36 and was lower compared with Szczecin (15.2) or Warszawa (13.8), with the national mean being 13.7.7 The mean number of teeth was higher only as compared to Torun (12.6). The national mean number of teeth in large cities was 14.3 and was higher compared to smaller towns (12.8). ${ }^{2}$ In the analysis of this parameter in correlation to gender, 14.4 teeth in men and 12.6 in women were observed. ${ }^{2}$ Recent Polish studies have shown a higher number of remaining teeth in men as compared to women (2), while in our study this difference was more pronounced -6 teeth. ${ }^{2}$ The mean numbers were 17.65 in men and 11.25 in women.

These observations are very optimistic compared to the national research from 1998 and 2002. At that time, the epidemiological situation related to the number of preserved teeth in Polish citizens aged 65-74 years was very poor. According to monitoring research in 1998, the mean number of teeth in the citizens of all provincial cities in the analyzed age group was 9.1 while edentulism amounted to $32.2 \%$. In 2002 this situation considerably deteriorated, as the mean number of teeth was 8.1 , while edentulism amounted to $35.6 \% .^{28}$

Another beneficial observation for this age group of Polish citizens is a significant decrease in the number of edentulism patients. In 2002 the percentage of edentulism was almost $44 \%$ while recent reports indicated $29 \%{ }^{2,7}$ Despite such a great improvement, the value of almost $29 \%$ of edentulism cases in Polish population aged 65-74 years still remains one of the highest in Europe. ${ }^{2}$

Own research showed a considerably lower edentulism percentage (12.5\%) compared to the national mean value. It is undoubtedly a positive phenomenon, yet considering the low reportability for epidemiology study, the obtained results ought to be interpreted very carefully.

The presence of at least 20 preserved natural teeth, which is indicative of a maintained masticatory function, was found in $27.78 \%$ of patients. The obtained result was higher than the Polish mean value, which was estimated at $25.15 \%{ }^{2}$ This result is 3 -fold lower than the goals of oral cavity health set by WHO for 2010 (the assumptions were $75 \%$ with minimum 20 preserved teeth). ${ }^{29}$ It is difficult to compare this outcome with this age group of Polish citizens in 2002 and 2009, since in those studies the maintained masticatory function was defined as at least 20 natural or artificial teeth in functional contact. ${ }^{8}$ In the available literature only one considerably up-to-date (2004) research of the Hungary population at this age was found and it showed 21 or more teeth in $22.6 \%$ of the individuals. $^{2,30}$

The prosthetic needs of the examined group were 2-fold smaller (12.5\%) compared to those in the study by Szpak et al. $^{3}$ In the male group from Białystok, $24.5 \%$ of persons needed full dentures, $36.8 \%$ showed edentulism in the maxilla while $27.4 \%$ in the mandible. According to our own research, a considerably higher number of patients (13.89\%) required rehabilitation of masticatory apparatus with the use of full dentures in the upper arch compared with edentulism in the mandible (2.78\%). In 1995 the percentage of both men and women from Białystok aged 60 years or more requiring full denture in the maxilla was $40.4 \%$ while in the mandible $36.2 \% .^{31}$ In 1991 , in the population of men and women of the north-eastern region of Poland aged $65-74$ years, $35.2 \%$ of persons required full dentures in the maxilla and the same percentage in the mandible. ${ }^{32}$ The analysis of the described correlations in the northeastern region of Poland indicates an improvement in prosthetic treatment among seniors, yet it is still unsatisfactory considering WHO guidelines for 2020 or even for $2010 .^{29,33}$

Based on the analysis of a number of epidemiology studies, WHO considerably changed the goals regarding oral cavity health in the age group 65-74 years for 2020 compared to 2010. Current guidelines are more general: decreasing the number of extracted teeth due to caries and periodontitis, decreasing the percentage of persons with edentulism, increasing the number of preserved natural teeth and increasing the percentage of persons with at least 20 preserved teeth as well as decreasing the development of tissue infections and oral mucosa disorders. ${ }^{33}$

The major limitation of the presented study was the low percentage (7.2\%) of reportability of randomly chosen individuals. In the case of the study of Health in Pomerania, the percentage of reportability of randomly chosen persons was 72.9 and 65.2 for women as well as 66.2 and $74.3 \%$ for men in the age groups of $40-49$ and $60-69$, respectively. ${ }^{34}$ Another limitation was related to the use of CPI and lack of reference to the observations related to the currently preferred measurement of probing depth (PD) and clinical attachment level (CAL) in study design. ${ }^{19,20}$ Despite the described limitations, the conducted epidemiology study of periodontal status in Białystok citizens proves that periodontitis constitutes a social disease. 
According to the number of own observations as well as that of other authors, significant causes impeding the improvement of oral health are as follows: lack of supporting policy and legal regulations in undertaking significant preventative and pro-health actions in Poland, low awareness of the importance of oral cavity health as well as cultural and social barriers. ${ }^{8}$ Therefore, scheduled periodontal prophylactic-therapeutic actions and accurately defined periodontal treatment in screening groups, e.g. diabetic patients or persons with past history of cardiovascular incident are necessary. Also, a change in pro-health habits of adult Poles (improved oral hygiene, fighting smoking) is needed. Establishing such guidelines is undoubtedly necessary.

\section{Conclusions}

Białystok citizens show improper oral hygiene and periodontal status. It is necessary to improve the effectiveness of dental health care system for elderly people.

\section{References}

1. Philstrom BL, Michalowicz BS, Johnson NW. Periodontal diseases. Lancet. 2005;366:1809-1820.

2. Konopka T, Dembowska E, Pietruska M, Dymalski P, Górska R. Periodontal status and the selected parameters of oral condition of Poles aged 65-74 years. Przegl Epidemiol. 2015;69:643-647.

3. Szpak A, Stokowska W, Gołębiewska E. Dentition status and treatment needs of 65-74-year-old men living in Białystok. Probl Hig Epidemiol. 2012;93:97-104 (in Polish).

4. Strużycka I, Adamowicz-Klepalska B. Priority action areas for global oral health according to the WHO. Czas Stomatol. 2005;58:450-456 (in Polish).

5. Brodzikowska N, Bujakowsa M, Kuźnicka E, Pietrzak D. Oral health in the elderly in Poland. Magazyn Stomatol. 1992:2(7):24-27 (in Polish).

6. Skrzypkowski A. Selected dental problems of older people. Stomatol Współcz. 2003;10:3:49-53 (in Polish).

7. Konopka T, Zawada $Ł$, Kobierzycka A, Chrzęszczyk D. Periodontal condition in 35-44 and 65-74 year-old residents from Lower Silesia Region. Dent Med Probl. 2015;52:447-454 (in Polish).

8. Jodkowska E. The condition of dentition status of adults Polish citizens in years 1998-2009. Przegl Epidemiol. 2010;64:571-576 (in Polish).

9. Iwanicka-Frankowska E, Wierzbicka M, Szatko F, Pierzynowska E, Zawadziński M. Oral health of Polish population's adults aged 65-74 in the last five years. Stomatol Współcz. 2003; 10(6):9-13 (in Polish).

10. O'Leary TJ, Drake RB, Naylor JE. The plaque control record. J Periodontol. 1972;43:38.

11. Lange DE, Plagmann HCh, Eenboom A, Promesberger A. Klinische Bewertungsverfahren zur Objektivierung der Mundhygiene. Dtsch Zahnarztl. Z. 1977;32:44-47.

12. Ainamo J, Bay I. Problems and proposals for recording gingivitis and plaque. Int Dent J. 1975;25:229-235.

13. Black SA, Rush RD. Cognitive and functional decline in adults aged 75 and older. J Am Geriatr Soc. 2002;50:1978-1986.

14. Szatur-Jaworska B. The aging of the Polish population - challenges for social policy. Gerontol Pol. 2002;10:199-205 (in Polish).

15. Wierucka-Młynarczyk B, Kubicka-Musiał M, Hüpsch-Marzec $H$. The growing population of older people as a challenge for dentists. As Stomatol. 2007:4:42-44 (in Polish).

16. Kaczmarczyk-Stachowska A, Knychalska-Karwan Z, Ciesielska M, Fijał D, Gawrzewska B. Indicator oral hygiene and periodontal changes in people aged 15-80 years, living in Cracow. Czas Stomatol. 2001;54:112-117 (in Polish).
17. Holmgren CJ. CPITN - Interpretations and limitations. Int Dent J. 1994;44:533-546.

18. Baelum V, Papapanoup N. CPITN and the epidemiology of periodontal disease. Community Dent Oral Epidemiol. 1996;24:367-368.

19. Zawada $\measuredangle$, Konopka T. New periodontal indices. Dent Med Probl. 2011;48:243-250 (in Polish).

20. Zawada $Ł$, Chrzęszczyk D, Konopka T. Definitions of periodontitis in selected group of Wrocław adult residents. Dent Med Probl. 2012;49:537-542 (in Polish).

21. Górski B, Ganowicz E, Górska R. Classic risk factors of cardiovascular diseases and periodontal status in patients after acute myocardial infarction. Dent Med Probl. 2015;52:269-280 (in Polish).

22. Thornton-Evans G, Eke $P$, Wei I, et al. Periodontitis among adults aged $\geq 30$ years - United States, 2009-2010. MMWR. 2013;62:129-135.

23. Górska R, Pietruska M, Dembowska E, Wysokińska-Miszczuk J, Włosowicz M, Konopka T. Prevalence of periodontal disease in 35-44 year-olds in the large urban agglomerations. Dent Med Prob. 2012;49:19-27 (in Polish).

24. Konopka T, Pietruska M, Dembowska E, Dymalski P, Górska R. Oral and periodontal condition in 65-74 year-old Poles. J Stoma. 2014;67(Supl.1):57-58 (in Polish)

25. Wojtyniak B, Goryński P, Moskalewicz B. The health situation of Poles and its determinants. Narodowy Instytut Zdrowia Publicznego - Państwowy Zakład Higieny, Warszawa 2012 (in Polish).

26. Faveri M, Rebello A, Dias Ro, et al. Clinical and microbiological effects of adjunctive metronidazole plus amoxicillin in the treatment of generalized chronic periodontitis: smokers versus nonsmokers. J Periodontol. 2014;85:581-591.

27. Eke Pi, Dye Ba, Wei L, Thornton-Evans G, Genco RJ. Prevalence of periodontitis in adults in the United States: 2009 and 2010. J Dent Res. 2012;91:914-920.

28. Jodkowska E, Wierzbicka M, Szatko F, et al. Oral health and its determinants and the need for prevention and treatment in children and adults aged 65-74 years. Warszawa 2009 (in Polish).

29. Banach J. What about execution of periodontal global goals for the year 2010 in Poland? Dent Med Probl. 2002;39:9-12 (in Polish).

30. Madléna $M$, Hermann $P$, Jáhm $M$, Fejérdy $P$. Caries prevalence and tooth loss in Hungarian adult population. BMC Public Health. 2008;8:364.

31. Namiot D, Sierpińska T, Gołębiewska M, Kobierska A. Evaluation of needs for removable dentures treatment in elderly patients. Protet Stomatol. 1995;45:295-300 (in Polish).

32. Szyszko T, Tokajuk G, Miksza-Żyłkiewicz R, Guckler A. Denture needs of inhabitants aged over 55 year in the north of Poland. Czas Stomatol. 1994;47:845-847 (in Polish).

33. Hobdell M, Petersen Pe, Clarkson J, Johnson N. Global goals for oral health 2020. Int Dent J. 2003;53:285-288.

34. Holtfreter B, Schwahn Ch, Biffar R, Kocher T. Epidemiology of periodontal diseases in the study of health in Pomerania. J Clin Periodontol. 2009;36:114-123. 